\title{
Reply to the letter to the editor on Prien-Larsen et al.: Influence of TVT properties of midurethral sling procedures: high-stiffness versus low-stiffness tape
}

\author{
Jens Christian Prien-Larsen ${ }^{1}$ Ram B. Dessau ${ }^{2}$
}

Received: 4 August 2016/Accepted: 28 August 2016/Published online: 19 September 2016

(C) The International Urogynecological Association 2016

\section{Dear Editor}

We thank Tony Bazi for his interest in our article [1]. He states that the title unrealistically promises more than it can deliver. We agree that the title could be misleading, and that the article is only about the impact of tape stiffness. As stated in the introduction, the aim was to compare outcome between a high-stiffness tape with smooth edges and a low-stiffness tape with rough edges.

We also agree that the behavior of the tape in the cure of SUI depends on a multitude of factors; the weight and composition of the mesh material are well-known important factors for healing and complications. Other properties, such as stiffness and elasticity but not the outer structure of the tape edges, have been examined in the laboratory, but not in vivo.

In contrast to our results, Bazi states that a high-stiffness tape would theoretically result in a higher cure rate and more obstructive effect. He justifies this conviction based on results from the use of high-stiffness rectus fascia with smooth edges compared with polypropylene tape and found similar or even better results for the former. We do not agree with this comparison because the polypropylene tape is self-retaining and not fixed with sutures, as is the case with the smooth highstiffness rectus fascia. If the position of the rectus fascia is not secured with sutures, it would slip like other high-stiffness

This reply refers to the comment available at doi:10.1007/s00192-016-3145-y

Jens Christian Prien-Larsen

jcpr@ regionsjaelland.dk

1 Department of Obstetrics and Gynecology, Nykøbing Falster Hospital, Fjordvej 15, 4800 Nykøbing Falster, Denmark

2 Department of Clinical Microbiology, Slagelse Hospital, 4200 Slagelse, Denmark tapes with smooth edges such as IVS and SOFT tapes. From our own unpublished data, we know that the pullout force for high-stiffness tape with smooth edges (IVS and SOFT tape) is significantly lower than tape with rough edges. Furthermore, the study by Alcalay et al. [2] shows that the implant is held in place during the initial postoperative days by the friction force. These observations are in accordance with a recently published study [3], which found progressively more mature collagen around the vaginal explants between 60 and 180 days.

In our opinion, the TVT tape is held in place during the initial postoperative period by three main variables:

1. The outer structure of the tape

2. The type of tissue the tape passes through

3. The strength of the tissue

We believe that the most important property of the tape is the rough surface, creating the friction force that holds the tape in place. Whether the stiffness of the tape plays any role in the cure of SUI is unknown and in our opinion doubtful.

Compliance with ethical standards

Conflicts of interest None.

\section{References}

1. Prien-Larsen JC, Prien-Larsen T, Cieslak L, Dessau RB. Influence of TVT properties on outcomes of midurethral sling procedures: highstiffness versus low-stiffness tape. Int Urogynecol J. 2016;27:1039-45.

2. Alcalay M, Livneh M, Braun NM, Tov YS, Hod E. Mesh pullout force: comparative study of different deployment techniques in a sheep model. Int Urogynecol J. 2014;25:103-7.

3. Feola A, Endo M, Urbankova I, et al. Host reaction to vaginally inserted collagen containing polypropylene implants in sheep. Am J Obstet Gynecol. 2015;212(4):474.e1-474.e8. 